\title{
Perbedaan perilaku prososial ditinjau dari jenis kelamin pada relawan sosial
}

\author{
Rahmah Fitroh \\ Magister Psikologi, Program Pascasarjana, Universitas Ahmad Dahlan \\ rahmahfitroh16@gmail.com \\ Wildani Khoiri Oktavia \\ Magister Psikologi, Program Pascasarjana, Universitas Ahmad Dahlan \\ viapsikologi12@gmail.com \\ Haris Hanifah \\ Fakultas Psikologi, Universitas Islam Negeri Maulana Malik Ibrahim Malang \\ harishanifah95@gmail.com
}

\begin{abstract}
ABSTRAK
Perilaku prososial pada relawan sosial belum terimplementasikan dengan baik. Perilaku individu menolong individu lain belum diberikan secara tulus dan belum mampu melakukan pengendalian emosi diri karena adanya perasaan negatif. Hal ini terjadi pada jenis kelamin perempuan dan laki-laki. Tujuan penelitian untuk menguji apakah ada perbedaan perilaku prososial ditinjau dari jenis kelamin pada relawan sosial. Metode penelitian ini adalah metode kuantitatif. Sampel yang digunakan berjumlah 37 relawan sosial yang terdiri dari 19 perempuan dan 18 laki-laki. Teknik yang digunakan adalah insidental sampling. Skala penelitian yang digunakan adalah skala perilaku prososial yang didasarkan pada teori Eisenberg dan Mussen. Hasil penelitian menunjukkan adanya perbedaan yang signifikan antara perilaku prososial jenis kelamin perempuan dan jenis kelamin laki-laki dengan selisih nilai mean 0,988.
\end{abstract}

Kata Kunci: Jenis Kelamin, Perilaku Prososial, Relawan Sosial.

\begin{abstract}
Prosocial behavior in social volunteers has not been implemented properly, helping other individuals has not given sincerely and has not been able to control their emotions due to negative feelings. This happens to the gender of women and men. This research aims to determine the differential of prosocial behavior between women and men. Research method used quantitive methods. The sample used amounted to 37 social volunteers consisted of 19 women and 18 men. The sampling technique was incidental sampling. The research scale used the scale of prosocial behavior according to prosocial behavior theory by Eisenberg and Mussen. The result of the analysis shows there is a contrast of prosocial behavior between women and men, has different score with mean score 0,988.
\end{abstract}

Keyword: Gender, Social Behavior, Social Volunteers.

\section{PENDAHULUAN}

Relawan sosial adalah individu yang memberikan waktunya untuk membantu individu lain secara sukarela, tanpa paksaan, dan tanpa bayaran (Kendall, 2012). Hal tersebut menunjukkan bahwa relawan 
Jurnal Psikologi Terapan dan Pendidikan

ISSN: $2715-2456$

Vol. 1, No. 1, Mei 2019, pp. 9-15

sosial merupakan individu yang tulus untuk membantu individu lain tanpa adanya upah atau gaji. Tujuan relawan sosial adalah membantu masyarakat untuk meningkatkan sumber daya sosial, menjawab kebutuhan sosial dan meningkatkan kesejahteraan diri para relawan (Zanbar, 2019).

Manfaat yang didapatkan menjadi relawan sosial adalah dapat mengurangi isolasi sosial (Priebe, Agnes, Thomas, Eoin, Michael \& Nancy, 2019). Membantu para relawan sosial untuk mengembangkan diri dan mendapatkan pengalaman baru (Wibowo, Ridwanudin, \& Rinaldi, 2019). Hal lainnya adalah relawan sosial cenderung merasa puas karena mendapatkan dukungan pada kegiatan sosial, dan menemukan bahwa pekerjaan yang dilakukan bersifat sukarela yang ditandai oleh otonomi dan perasaan kemanjuran (Florian, Jana \& Dan, 2019).

Relawan sosial ada pada organisasi-organisasi di lembaga sosial. Keikutsertaan untuk menjadi relawan sosial pada suatu organisasi dapat diikuti oleh setiap individu, tidak hanya golongan muda, juga dapat diikuti oleh golongan tua. Hasil survey yang dilakukan di Amerika Serikat, usia termuda yang terlibat menjadi relawan sosial adalah remaja yang berusia 16 sampai 19 tahun dan orang dewasa 45 tahun keatas (Voluntering in United States, 2013).

Sifat yang dimiliki relawan sosial yaitu bekerja demi kepentingan indvidu lain dan tidak mengharapkan imbalan dari perilakunya. Hal ini menunjukkan bahwa relawan sosial mencerminkan perilaku prososial. Perilaku prososial merupakan perilaku yang menguntungkan individu lain yang dilakukan secara sukarela dan tanpa keuntungan yang nyata bagi individu yang memberikan bantuan (Baron \& Byrne, 2012). Pentingnya memiliki perilaku prososial adalah dapat menurunkan perilaku agresif individu dan memperkuat sumber daya positif (Mesurado, Paulina, Maria, \& Lucas, 2018). Hal lain dapat memberikan sikap percaya dan menunjukkan sikap alturuisme terhadap individu lain (Crutchfield, Richard, Rebecca, Tyler, Ryan, Kevin \& Duncan, 2019).

Konsep perilaku prososial dibuktikan berdasarkan hasil penelitian yang dilakukan oleh (Klein, 2016) bahwa individu yang memiliki perilaku prososial membantu individu tanpa bergantung pada timbal balik individu lain. Individu yang tidak memiliki perilaku prososial dapat menimbulkan dampak negatif yaitu mengalami viktimisasi relasional dan dapat memiliki kosekuensi sosial-emosional negatif, misalnya perilaku antisosial dan penggunaan narkoba (Rusby, Michael, Jeff, Erika, John, Jeremy, Nikola \& Brian, 2019).

Faktor yang mempengaruhi perilaku prososial yaitu faktor situasional dan faktor dalam diri (Baron, Byrne \& Branscombe, 2006). Faktor yang berasal dari dalam diri invidu salah satunya adalah jenis kelamin. Faktanya, perilaku prososial pada relawan sosial belum terimplementasikan dengan baik pada relawan sosial. Hasil wawancara dengan relawan sosial menyatakan bahwa individu menolong 
Jurnal Psikologi Terapan dan Pendidikan

ISSN: 2715-2456

Vol. 1, No. 1, Mei 2019, pp. 9-15

individu lain belum memberikan secara tulus dan belum mampu mengendalikan emosi diri karena adanya perasaan negatif. Hal ini terjadi pada jenis kelamin perempuan dan laki-laki.

Berdasarkan pemaparan diatas peneliti tertarik untuk meneliti perbedaan perilaku prososial ditinjau dari jenis kelamin pada relawan sosial. Tujuan penelitian ini adalah untuk menguji apakah ada perbedaan perilaku prososial ditinjau dari jenis kelamin pada relawan sosial.

\section{METODE PENELITIAN}

Subjek yang digunakan pada penelitian ini adalah relawan sosial. Populasi penelitian ini berjumlah 100 relawan sosial, dengan kriteria subjek berkisar usia 18-35 tahun dan berstatus sebagai relawan sosial. Sampel yang diambil menggunakan teknik insidental sampling yang berjumlah 37 relawan sosial. Metode pengumpulan data pendekatan kuantitatif menggunakan skala likert. Skala yang digunakan yaitu skala prososial dari tokoh Eisenberg dan Mussen (1989) sebagai acuan penelitiaan.

Uji validitas dan reliabilitas menggunakan korelasi product moment. Uji validitas dengan pengambilan keputusan $r$ hitung $>0,3$ dinyatakan valid. Hasil menunjukkan bahwa terdapat 30 aitem valid yaitu $>0,3$ dan 10 item yang gugur yaitu $<0,3$. Uji reliabilitas menggunakakan alpha cronbach dengan standar reliabilitas 0,7-0,8 dikatakan baik dan reliabel. Hasil uji reliabilitas yaitu 0,942 dengan standar reliabilitas mendekati 1, sehingga skala dinyatakan reliabel. Analisis data menggunakan SPSS (Statistical Program for Social Science) untuk menguji validitas, reliabilitas, normalitas, homogenitas dan uji hipotesis.

\section{HASIL}

Hasil uji normalitas menggunakan uji shapiro wilk dapat dilihat berdasarkan tabel berikut:

Tabel 1.

Hasil Uji Normalitas

\begin{tabular}{llcccccc}
\hline & \multicolumn{4}{c}{ Kolmogorov-Smirnov ${ }^{\mathrm{a}}$} & \multicolumn{3}{c}{ Shapiro-Wilk } \\
\hline \multirow{3}{*}{ Prososial } & JenisKelamin & Statistic & Df & Sig. & Statistic & Df & Sig. \\
& Perempuan & .157 & 19 & $.200^{*}$ & .915 & 19 & .092 \\
& Laki-laki & .194 & 18 & .073 & .945 & 18 & .351 \\
\hline
\end{tabular}

Hasil uji normalitas menunjukkan nilai signifikansi (Sig.) pada perempuan 0,092 >0,05 dan Sig. pada laki-laki 0,351 >0,05. Hal ini dapat disimpulkan bahwa perilaku prososial pada relawan sosial jenis 
Jurnal Psikologi Terapan dan Pendidikan

ISSN: 2715-2456

Vol. 1, No. 1, Mei 2019, pp. 9-15

kelamin perempuan dan laki-laki berdistribusi normal. Hal ini dapat dilihat dari gambar 1, Normal Q-Q Plot of Prososial Behavior dibawah ini:

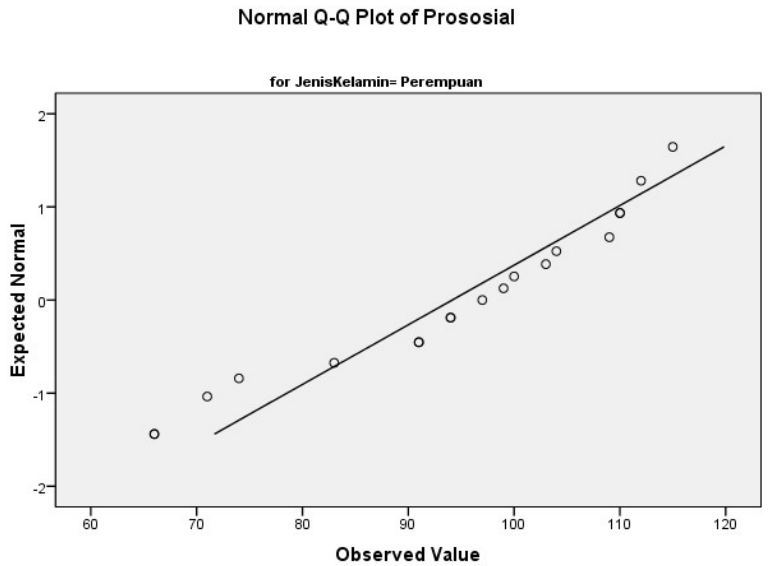

Gambar 1. Normal Q-Q Plot of Prososial pada Perempuan

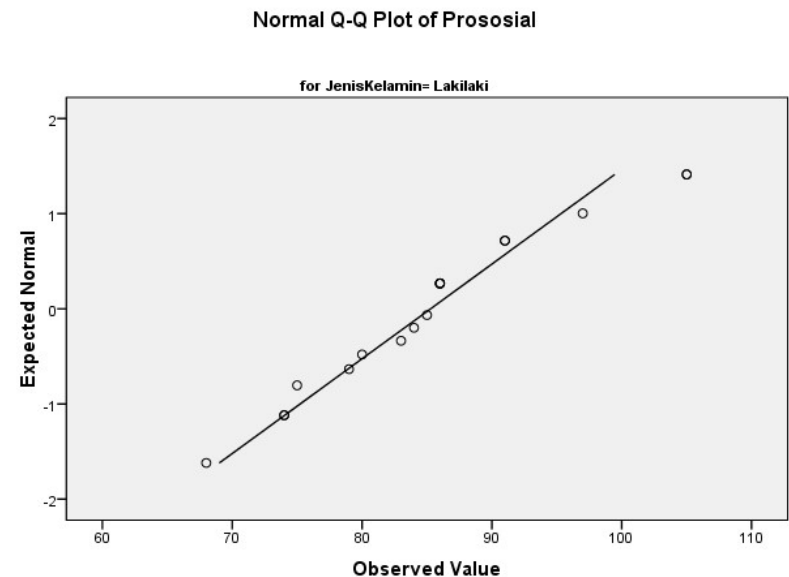

Gambar 2. Normal Q-Q Plot of Prososial pada Laki-Laki

Hasil uji normalitas dapat dilihat berdasarkan sebaran titik-titik yang ada pada gambar. Apabila sebaran titik-titik mendekati atau rapat dengan garis lurus (diagonal) maka dapat dikatakan bahwa data berdistribusi normal. Hasil uji homogenitas dengan nilai Sig. 0,062 > 0,05, dapat disimpulkan berdasarkan pengambilan keputusan bahwa data perilaku prososial pada jenis kelamin perempuan dan laki-laki adalah homogen, dapat dilihat pada tabel berikut:

Tabel. 2

Hasil Tes Homogenitas

$\begin{array}{llll}\text { Levene Statistic } & \text { df1 } & \text { df2 } & \text { Sig. }\end{array}$




$\begin{array}{llll}3.717 & 1 & 35 & .062\end{array}$

Uji hipotesis menggunakan uji independent sample t-test untuk mengetahui apakah ada perbedaan perilaku prososial ditinjau dari jenis kelamin perempuan dan laki-laki pada relawan sosial, adapun hasil perhitungannya sebagai berikut:

Tabel. 3

Hasil Uji Hipotesis

Variabel Jenis Kelamin Mean Sig (2-tailed)

Perilaku Perempuan $\quad 94.15$

$\begin{array}{llll}\text { Prososial } & \text { Laki-laki } & 85.27 & 0.049\end{array}$

Berdasarkan tabel di atas nilai rata-rata perilaku prososial jenis kelamin perempuan 95,15 dan nilai- rata-rata perilaku prososial jenis kelamin laki-laki 85,27. Hal ini menunjukkan secara deskriptif statistik terdapat perbedaan rata-rata perilaku prososial antara jenis kelamin perempuan dan laki-laki dengan selisih 9,88. Hasil independent simple t-test dengan signifikansi (Sig.) nilai 0,049<0,05. Hal ini menunjukkan bahwa $\mathrm{H} 0$ ditolak dan Ha diterima, maka terdapat perbedaan yang signifikan antara perilaku prososial jenis kelamin perempuan dan jenis kelamin laki-laki.

\section{PEMBAHASAN}

Hasil hipotesis yang telah diuraikan diatas, menyatakan bahwa ada perbedaan perilaku prososial berdasarkan jenis kelamin. Hal ini menunjukan faktor dalam diri mempengaruhi perilaku prososial, dimana perilaku prososial perempuan lebih tinggi dibandingkan perilaku prososial laki-laki. Sarwono, Sarlito dan Eko (2009) menegaskan bahwa dengan adanya perbedaan jenis kelamin, suatu lembaga sosial dapat menentukan siapa yang akan diterjunkan pada suatu situasi dengan berdasarkan pada situasi dan bentuk pertolongan yang dibutuhkan.

Relawan sosial perempuan berdasarkan aspek perilaku prososial memiliki rasa persahabatan yang tinggi. Relawan perempuan memiliki kesediaan untuk menjalin hubungan yang lebih dekat dengan individu lain. Relawan perempuan juga menunjukan aspek bertindak jujur, mereka melakukan tindakan tanpa berbuat curang. Serta aspek berderma, yaitu memberikan secara sukarela sebagian barang yang dimiliki kepada individu yang membutuhkan. Aspek tersebut yang belum ditunjukkan oleh jenis kelamin laki-laki. Laki-laki lebih menunjukkan pada aspek kerjasama, dimana kesediaan untuk berkerjasama 
Jurnal Psikologi Terapan dan Pendidikan

ISSN: $2715-2456$

Vol. 1, No. 1, Mei 2019, pp. 9-15

dengan individu lain dalam pencapaian tujuan lebih menonjol dan aspek menolong yaitu kesediaan dalam menolong individu lain dalam kesulitan.

Hasil penelitian ini sejalan dengan penelitian yang dilakukan oleh Celeste, Marcia dan Juan (2011) menunjukkan bahwa perempuan lebih tinggi dalam keinginan untuk membantu dan diterima oleh individu lain dan memiliki identitas peran yang lebih besar daripada laki-laki. Ada perbedaan jenis kelamin yang mencolok pada pengembangan perilaku prososial pada penelitian yang dilakukan oleh Van der Graaff, Susan, Gustavo, Elisabetta dan Hans (2018). Laki-laki tingkat prososial stabil hingga berusia 14-17 tahun dan mengalami penurunan setelahnya. Tingkat perilaku prososial perempuan meningkat hingga usia 16 tahun dan setelahnya sedikit menurun. Paz Espinosa dan Jaromir (2015) menjelaskan bahwa secara umum laki-laki dan perempuan tidak berbeda, akan tetapi pembingkaian sosial cenderung memperkuat perilaku prososial pada perempuan tetapi tidak pada laki-laki. Hal ini menunjukkan berdasarkan penelitian yang sejenis menguatkan bahwa perilaku prososial perempuan lebih tinggi daripada laki-laki.

\section{KESIMPULAN}

Relawan sosial perempuan mempunyai perilaku prososial lebih tinggi dibandingkan lakilaki. Hal ini berdasarkan nilai rata-rata yang didapatkan dengan selisih diantara keduanya adalah 9,88. Relawan sosial perempuan lebih menunjukkan perilaku prososial pada aspek persahabatan, bertindak jujur dan berderma, sedangkan relawawan sosial laki-laki menunjukkan pada aspek kerjasama dan menolong. Berdasarkan hasil penelitian ini dapat disimpulkan bahwa perempuan bertindak berdasarkan psikis dan laki-laki bertindak berdasarkan pada fisik.

\section{DAFTAR PUSTAKA}

Baron, R. A., Byrne, D., \& Branscombe. (2006). Social psychology (Edisi II). Boston: Allyn and Bacon.

Baron, R. A., \& Byrne, D. (2012). Psikologi sosial. Jakarta: Erlangga.

Celeste, M. D., Marcia, A. F., \& Juan, I. C. (2011). Gender differences in prosocial behavior: Organizational citizenship behavior. Anales de Psicologia, 27(2), 498-506.

Crutchfield, P., Richard, B., Rebecca, F., Tyler, G., Ryan, K., Devin, S \& Duncan, V. (2019). Prosocial Behavior of Medical Students: An Experiment Using the Trust Game. WMU Homer Stryker M.D. School of Medicine.

Florian, M., Costas, J., \& Kärreman, D. (2019). Struggling with meaningfulness when context shifts: Volunteer work in a German refugee shelter. Journal of Management Studies, 56(3), 589-616.

Kendall, J. (2012). The voluntary and community sector. New York: Oxford. 
Klein, N. (2016). Prosocial behavior increas perceptions of meaning in life. The Journal of Positive Psychology.12(4), 354-361.

Mesurado, B., Paulina, G., Maria, C. R., \& Lucas, M. R. (2018). Effectiveness of Prosocial behavior interventions: A meta-analysis. In Psychiatry and Neuroscience Update.(pp. 259-271). Spinger, Cham.

Paz, E. M., \& Jaromir, K. (2015). Prosocial behavior and gender. Frotiers in Behavioral Neuroscience, 9(1), 1-9.

Rusby, J. G., Michael, M., Jeff, M. G., Erika, W., John, M. L., Jeremy, M., Nikola, M. Z., \& Brian, R. F. (2019). Relational victimixation and peer affiliate prosocial behaviors in African American Adolescents: Moderating efects of gender and antisocial behavior. Journal of Adolescence, 71(1), 91-98.

Sarwono, S, W., \& Eko, A. M. (2009). Psikologi sosial. Jakarta: Salemba Humanika.

Priebe, S., Chevalier, A., Hamborg, T., Golden, E., King, M., \& Pistrang, N. (2019). Effectiveness of a volunteer befriending programme for patients with schizophrenia: Randomised cotrolled trial. The British Journal of Psychiatry, 1-7.

Wibowo, L. A., Ridwanudin, O., \& Rinaldi, A. R. (2019, June). Volunteer tourism experience in friends of The National Parks Foundation. In 3rd International Seminar on Tourism (ISOT 2018). Atlantis Press.

Van D. G. J., Susan, B., Gustavo, C., Elisabetta, C., \& Hans, M. K. (2018). Prosocial behavior in Adolescence: Gender differences in development and links with empathy. Journal Youth Adolescence, 47(1), 1086-1099.

Voluntering in United States. (2013). Diakses pada 3 Agustus 2019.

Zanbar, L. (2019). The effect of volunteering for community activity on the social resources of low-SES residents: Differences between volunteer community activist and other residents. International Journal of Voluntary and Nonprofit Organizations, (30)1, 164-174. 